\title{
昡pubvet
}

https://doi.org/10.31533/pubvet.v13n8a383.1-9

\section{Produção e caracterização de farinha de silagem química de pescado, destinada à piscicultura}

\author{
Dariane Beatriz Schoffen Enke ${ }^{1 *} \bullet$, Paulo Rodinei Soares Lopes $^{2} \bullet$, Cleber Bastos Rocha ${ }^{30}$, \\ Juvêncio Luiz Osório Fernandes Pouey ${ }^{4} \bullet$ \\ ${ }^{I}$ Professora Assistente Doutor, Universidade Estadual Paulista Júlio de Mesquita Filho, Campus Experimental de Registro,SP, Brasil. \\ ${ }^{2}$ Professor Adjunto, Universidade Federal do Pampa, UNIPAMPA, Brasil. ${ }^{3}$ Médico Veterinário, Doutor em Ciências. \\ ${ }^{4}$ Professor Adjunto, Doutor, Departamento de Zootecnia (UFPel) Pelotas-RS, Brasil.E-mail: juvencio@ufpel.tche.br \\ *autor para correspondência, E-mail: dariane.enke@unesp.br
}

\begin{abstract}
Resumo. A silagem química de peixe é um produto líquido feito com peixes inteiros ou partes deles, com adição de um ácido ou mistura, sendo que a liquefação da massa se faz pela ação de enzimas já presentes no peixe. O objetivo deste trabalho foi avaliar o aproveitamento dos rejeitos do peixe de água doce, conhecido como birú ou voga (Cyphocharax voga). É uma espécie sem valor comercial, encontrada em abundância no Rio Grande do Sul pelos pescadores artesanais, sendo descartada logo após a sua captura, constituindo problema para os pescadores, meio ambiente e as indústrias. Além de serem poluentes, são desperdiçados produtos de alto valor nutritivo. A silagem com ácido acético foi elaborada de rejeitos de pescado moído, adicionando-se $10 \%$ daquele ácido, a temperatura ambiente durante 15 dias com $\mathrm{pH}$ monitorado diariamente. Foram realizadas análises de composição química, aminoácidos e minerais. Os resultados mostraram que a farinha de silagem de pescado obtida foi satisfatória, contribuindo para a diminuição da poluição ambiental e utilização de um produto promissor para a piscicultura. Ao final da hidrólise a composição proteica foi de $62 \%$, apresentando praticamente a mesma composição da matéria-prima (teor de proteína de 55,49\%, 20,79\% de lipídios e 23,12\% de minerais totais). A farinha de silagem apresentou adequada composição em aminoácidos e minerais, sugerindo a utilização da mesma, preparada a partir dos rejeitos da pesca de água doce, como fonte proteica na formulação de ração para peixes.
\end{abstract}

Palavras chave: Ácido acético, Cyphocharax voga, pescado, rejeito

\section{Production and characterization of flour chemistry of fish silage, destined to aquaculture}

Abstract. Chemical fish silage is a liquid product elaborated with whole fish or parts of them, with the addition of a few acids or mixture of them, with the liquefaction of the mass being done by enzymes already present in fish. The objective of this study was to evaluate the utilization of fresh water fish Voga (Cyphocharax voga). This species is of low commercial value, found abundantly in Rio Grande do Sul and captured by nonprofessional fishermen, being discarded soon after capture constituting a problem for fishermen and industries. Besides being poluents, highly nutritive products are wasted. Acetic acid silage was elaborated with ground fish dregs, added $10 \%$ acetic acid during 15 days and $\mathrm{pH}$ monitored daily. Amino acids, minerals and chemical composition analyses were performed. Results showed that the production of fish chemical silage was satisfactory, allowing decrease in environment pollution and utilization of a promising product in pisciculture. At the end of hydrolysis the protein composition was of $62 \%$ showing practically the same composition of the raw material (protein content of 55.49\%, 
$20.79 \%$ lipids and $23.12 \%$ of total minerals). Silage presented adequate aminoacid and mineral composition, suggesting the utilization of this silage, prepared from fresh water fish dregs, as protein source in fish ration formulation.

Keywords: Acetic acid, Cyphocharax vog, discards, fishing

\title{
Producción y caracterización de harina de ensilaje química de pescado destinada a la piscicultura
}

\begin{abstract}
Resumen. El ensilaje químico de pescado es un producto líquido hecho con peces enteros o partes de ellos, con adición de un ácido o mezcla, la condensación de esta masa se realiza por la acción de enzimas presentes en el pescado. El objetivo de este trabajo fue evaluar el aprovechamiento de los desechos del pescado Cyphocharaxvoga (conocido como Biru o Voga) de agua dulce. Es una especie sin valor comercial, encontrada en abundancia en Rio Grande del Sur por los pescadores artesanales, siendo desechada después de su captura, siendo un problema para los pescadores, el medio ambiente y las industrias. Además de ser contaminantes, se pierden productos de alto valor nutritivo. El ensilaje fue elaborado con desechos de pescado molido, añadiendo $10 \%$ de ácido acético a temperatura ambiente durante 15 días con $\mathrm{pH}$ monitoreado diariamente. Se realizaron análisis de composición química, aminoácidos y minerales. Los resultados mostraron que la harina de ensilaje de pescado obtenida fue satisfactoria, contribuyendo a la disminución de la contaminación ambiental y utilización de un producto prometedor para la piscicultura. Al final de la hidrólisis, la composición proteica fue de $62 \%$, presentando prácticamente la misma composición de la materia prima (contenido de proteína de 55,49\%, 20,79\% de lípidos y $23,12 \%$ de minerales totales). La harina del ensilaje presentó adecuada composición en aminoácidos y minerales, sugiriendo la utilización de la misma, preparada a partir de los desechos de la pesca de agua dulce, como fuente proteica en la formulación de concentrado para pescados.
\end{abstract}

Palabras clave: Ácido acético, Cyphocharaxvoga, pescado, rechazo

\section{Introdução}

Existem várias espécies de pescado de pequeno porte e de baixo ou nenhum valor comercial, que são capturadas juntamente com o pescado destinado a comercialização; uma destas espécies é a Voga ou também conhecida como Biru (Cyphocharax voga), é um peixe de água doce de pequeno porte que atinge em torno de $20 \mathrm{~cm}$, que vive no Brasil (em especial no Rio Grande do Sul e no sudoeste de Santa Catarina), Uruguai, Argentina e Paraguai (Vari, 1988). No RS esta espécie é encontrada em abundância em lagoas e arroios na região sul, sendo citada a Lagoa dos Patos conforme Garcia \& Vieira Sobrinho (2001) e Lagoa Emboaba (Hartz et al., 1994). Segundo dados do IBAMA, no ano de 2005 foram desembarcados um total de 23 toneladas e no ano de 2006, 16 toneladas nos municípios de Pelotas, Rio Grande e São Lourenço do Sul, sendo este, um rejeito da pesca artesanal de água doce.

$\mathrm{O}$ aproveitamento desses rejeitos na forma de silagem trará vantagens econômicas, permitirá o aparecimento de novos produtos e eliminará o problema de poluição ambiental. Para o preparo da silagem química, primeiramente a matéria-prima deve ser moída e logo após, adicionado o ácido na proporção de 10\% p/v (Gupta \& Acosta, 2004)), homogeneizada à temperatura ambiente. Após a mistura inicial, o processo de fermentação começa naturalmente. Um revolvimento do material facilita a ação das enzimas normalmente presentes na carne do pescado, com a consequente hidrólise das proteínas e formação da silagem (Arruda \& Oetterer, 2005; Oetterer et al., 2006). O processo de produção de silagem é simples, prático, econômico e acessível em pequena escala não exigindo equipamentos e procedimentos custosos ou mão-de-obra especializada. A silagem de peixe é atualmente utilizada para ração animal como fonte de proteína nobre de alto valor biológico, não devendo ser considerada como um competidor da farinha de peixe e sim como uma alternativa (Vidotti et al., 2002). Segundo Arruda et al. (2001), entre as vantagens da produção da silagem em relação à farinha de peixe, pode-se citar que o produto é a maior digestibilidade. O processo é virtualmente independente de escala, a tecnologia é simples mesmo para produção em larga escala, o capital gasto é pequeno, os efluentes e odores são 
reduzidos, não é necessário armazenamento do produto refrigerado, o processo é rápido em climas tropicais e o produto pode ser utilizado de imediato (Beerli et al., 2004). A silagem de pescado é usada na Escandinávia na alimentação de outros animais e peixes, dado o seu alto valor nutritivo (Das et al., 1993). A silagem líquida de pescado é fonte de proteína de alta qualidade e minerais para a alimentação animal; é versátil e pode ser utilizada como suplemento da ração de vários animais, como peixes, suínos, ovinos, bovinos e aves domésticas. A preservação se mantém por mais de um ano e o aroma desprendido é ácido (Sales, 1995).

Pezzato et al. (1995) salientam que a meta das indústrias produtoras de rações animais é a utilização de subprodutos da agroindústria, a fim de minimizar os custos operacionais, agregando valor aos produtos, além de qualidade nutricional às rações. Miranda \& Maggi (1991) comentam que se deve evitar o emprego de espécies com elevado teor lipídico como matéria-prima da silagem, devido à rápida deterioração deste, e redução da qualidade do produto final, sendo recomendável mesclar a matériaprima como peixes magros e gordos. É importante a determinação da qualidade do produto ao término do processamento de silagem por meio de ensaios biológicos com bovinos, porcos, aves e outros, para determinar a adequação da silagem ao animal desejado.

O maior problema na utilização de silagem de resíduos de pescado é o excesso de minerais, acarretado por cabeças e ossos existentes no resíduo. Visto que é inconveniente separá-los na indústria, deve-se tentar diminuir esta quantidade, a fim de que a silagem possa ser empregada em maiores proporções na dieta de animais (Arruda \& Oetterer, 2005; Conte Júnior \& Rodrigues, 2013). De acordo com Beraquet \& Galacho (1983), a hidrólise proteica, ocorrida na armazenagem da silagem, provoca um aumento na digestibilidade das proteínas, devido ao fato de que os aminoácidos ficam livres, aumentando o valor nutricional da mesma.

O objetivo deste trabalho foi o preparo e a caracterização físico-química e nutricional da silagem química de rejeitos da pesca de água doce e a obtenção de farinha para o seu emprego na alimentação de peixes.

\section{Material e métodos}

A elaboração da silagem foi realizada no Laboratório de Ictiologia do Departamento de Zootecnia da Universidade Federal de Pelotas (UFPel). Os rejeitos da pesca de Birí (Cyphocharax voga) foram moídos em máquina elétrica de moer carne e armazenados em baldes plásticos. Após homogeneização manual foi incluído ácido acético glacial P.A. na proporção de $10 \%$ do peso do resíduo moído, conforme recomendado por Seibel \& Souza-Soares (2003) acrescidos de antioxidante BHT (hidroxibutilanisil) na concentração de $0,02 \mathrm{~g} / 100 \mathrm{~g}$ sendo novamente homogeneizada.

A silagem foi armazenada em temperatura ambiente com média máxima de $23,5^{\circ} \mathrm{C}$ e mínima de $18^{\circ}$ $\mathrm{C}$ acompanhada por termômetro de mercúrio. $\mathrm{O}$ revolvimento foi executado nos cinco primeiros dias da silagem, para que o ácido entrasse em contato com a matéria-prima, uniformemente. $\mathrm{O}$ acompanhamento do $\mathrm{pH}$ foi realizado com potenciômetro digital. A silagem foi seca em secador bandeja com circulação de ar por $\pm 24 \mathrm{~h}$ a $55^{\circ} \mathrm{C}$ e moída, obtendo-se assim, uma farinha de silagem. O acompanhamento do grau de hidrólise foi pela precipitação com TCA 40\%, sendo no filtrado determinado o nitrogênio solúvel por macroKjeldahl. A composição bromatológica da matéria-prima e da farinha de silagem foram determinadas conforme AOAC (2005). Após a preparação da silagem, foi realizado um acompanhamento visando à cor, aroma e textura.

A determinação dos minerais nas farinhas de silagem e de pescado comercial foi realizada no Laboratório de Química e Fertilidade do Solo, no Departamento de Solos da Faculdade de Agronomia Eliseu Maciel - UFPel, de acordo com metodologia descrita em Tedesco et al. (1995), com digestão por via úmida: $\mathrm{H}_{2} \mathrm{O}_{2}$ e $\mathrm{H}_{2} \mathrm{SO}_{4}$ para $\mathrm{N}, \mathrm{P}, \mathrm{K}, \mathrm{Ca}$ e $\mathrm{Mg} ; \mathrm{HNO}_{3}$ e $\mathrm{HClO}_{4}$ para $\mathrm{Zn}, \mathrm{Cu}, \mathrm{Mn}$ e $\mathrm{Fe}$ e quantificação por espectrofotometria de absorção atômica. Estas mesmas farinhas foram desengorduradas e avaliadas em aparelho analisador de aminoácidos no Centro de Química de Proteínas da Faculdade de Medicina de Ribeirão Preto - USP, de acordo com a metodologia de (Spackman et al., 1958). O tipo de hidrólise foi alcalina para o triptofano e ácida para os demais aminoácidos. 
A determinação escore químico foi feita conforme Sgarbieri (1987) e calculado tomando-se como referência o padrão da FAO (1985), pela relação entre o teor de cada aminoácido essencial com o teor do aminoácido correspondente de uma proteína padrão.

\section{Resultados}

A silagem substitui o aroma característico do peixe em pouco tempo (cerca de 1 ou 2 dias), dando lugar a um cheiro ácido, que também era forte no início e se tornou brando com o decorrer dos dias. A Figura 1 representa a variação média do $\mathrm{pH}$ durante os 15 dias de processamento e após 30 dias de armazenamento.

$\mathrm{O}$ pH inicial foi próximo de 6,5 que é o pH da matéria-prima e logo após a adição de ácido acético ao rejeito da pesca, em torno de 4 o qual se manteve constante durante todo o processo, sendo que este valor é capaz de inibir o crescimento da maioria das bactérias patogênicas. Até o oitavo dia do processo, o teor de nitrogênio solúvel aumentou muito rápido, seguindo uma menor variação até o final do experimento, no décimo quinto dia de processo, onde a silagem apresentou o teor de nitrogênio solúvel de $62 \%$, em relação ao nitrogênio total. A variação dos teores de nitrogênio solúvel resultante da hidrolise proteica pode ser visualizado na Figura 2.

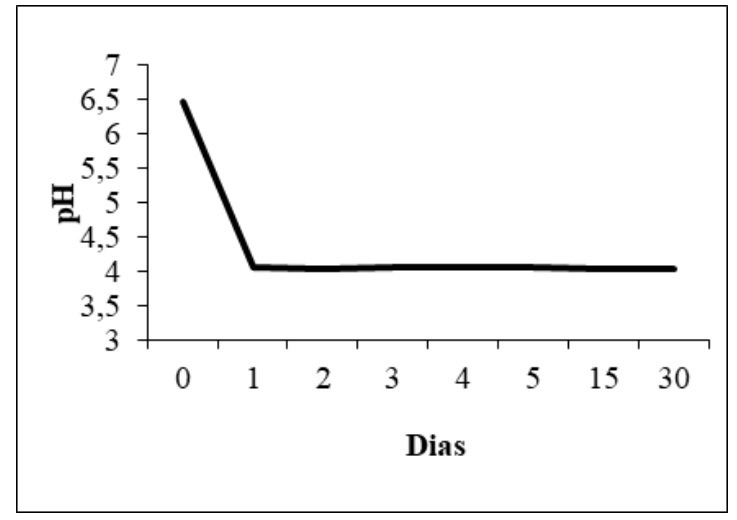

Figura 1. Variação do $\mathrm{pH}$ da silagem ao longo do período de elaboração.

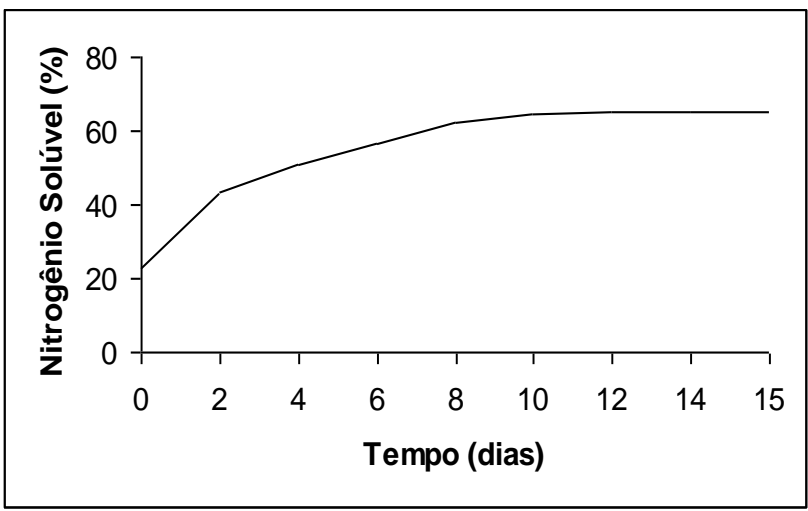

Figura 2. Teores de nitrogênio solúvel durante os 15 dias de silagem.

A textura pastosa foi se tornando líquida e, ao término de uma semana, todo o material estava em partículas menores do que as iniciais, tornando o produto praticamente líquido. Após uma semana, o produto está pronto para ser utilizado, mas observa-se que o ácido continuava agindo, tornando a silagem ainda mais líquida. A coloração inicial da massa homogênea passou de marrom com tons avermelhados para marrom-claro ao final do processo. A Tabela 1 mostra os valores de composição proximal do rejeito da farinha de silagem obtida e da farinha de pescado comercial. O processo de secagem $\left(24 \mathrm{hrs} \mathrm{a} 55^{\circ} \mathrm{C}\right)$ foi eficiente, pois a farinha de silagem apresentou um teor de umidade de $9,91 \%$ valor este, menor que da farinha de pescado comercial 10,03\%. Segundo Cunha \& Pinto (2002), teores de umidade considerados ideais para a farinha de pescado comercial variando de 9 a $13 \%$.

Tabela 1. Composição proximal (\%) do rejeito, da farinha de silagem e da farinha de pescado comercial.

\begin{tabular}{lcccc}
\hline Amostra & Umidade & Proteína Bruta* & Extrato Etéreo* & Minerais Totais* \\
\hline Rejeito de voga & 70,01 & 55,18 & 20,90 & 23,73 \\
Farinha de silagem de pescado (voga) & 9,91 & 55,49 & 20,79 & 23,12 \\
Farinha de pescado comercial & 10,03 & 52,69 & 9,94 & 35,37 \\
\hline
\end{tabular}

* base seca (média de 3 repetições).

Ainda que os teores de proteína bruta, minerais totais e extrato etéreo não se modificaram com o processo, sendo praticamente os mesmos para o rejeito e a farinha de silagem em base seca. O teor de extrato etéreo da farinha de silagem apresentou-se superior $(20,8 \%)$ ao da farinha de pescado comercial $(9,94 \%)$, esta diferença ocorre devido ao processamento de farinha de pescado comercial possuir uma etapa de retirada do óleo, e neste processamento de silagem não ocorreu a retirado o óleo. A composição 
de minerais da farinha de silagem e da farinha de pescado comercial tradicional está presente na tabela 2 , onde os teores de macroelementos estão expressos em $\mathrm{g} / \mathrm{kg}$ de amostra, enquanto que os micros elementos estão em $\mathrm{mg} / \mathrm{kg}$ de amostra.

Tabela 2. Composição de média do macro e microelementos minerais das farinhas de silagem e comercial.

\begin{tabular}{lllllllll}
\hline & \multicolumn{3}{l}{ Macroelementos $\mathrm{g} / \mathrm{kg}$} & \multicolumn{4}{c}{ Microelementos $\mathrm{mg} / \mathrm{kg}$} \\
\hline & Cálcio & Potássio & Fósforo & Magnésio & Cobre & Zinco & Ferro & Manganês \\
Farinha de Silagem de Pescado & 233,27 & 5,80 & 31,54 & 3,00 & 20,13 & 66,85 & 452,00 & 64,17 \\
Farinha de Pescado Comercial & 212,11 & 3,37 & 47,55 & 2,19 & 5,88 & 66,66 & 687,45 & 38,79 \\
\hline
\end{tabular}

Média de duplicata.

Em relação aos macros elementos, somente o potássio apresentou valor superior ao da farinha de pescado comercial e para os micros elementos somente o ferro apresentou valor inferior à farinha comercial. Ressalta-se que o nível de cálcio, em geral, são os mais limitantes, não apresentou valor muito maior que o da farinha de pescado comercial, potencializando um maior acréscimo de utilização da farinha de silagem nas rações animais. A Tabela 3 apresenta o resultado da análise de aminoácidos da farinha de silagem, comparada com a farinha de pescado comercial, e os escores químicos dos aminoácidos essenciais.

Tabela 3. Análise de aminoácidos das farinhas (g/100g proteína), escores químicos e padrão da FAO.

\begin{tabular}{|c|c|c|c|c|c|}
\hline \multirow[t]{2}{*}{ Aminoácidos } & \multicolumn{2}{|c|}{ Farinha de Silagem de Pescado } & \multicolumn{2}{|c|}{ Farinha de pescado comercial } & \multirow{2}{*}{$\frac{\text { FAO }}{\mathrm{g} / 100 \mathrm{~g}}$} \\
\hline & $\mathrm{g} / 100 \mathrm{~g}$ & EQ & $\mathrm{g} / 100 \mathrm{~g}$ & EQ & \\
\hline Triptofano* & 1,442 & 1,442 & 0,658 & 0,66 & 1,00 \\
\hline Lisina* & 4,325 & 0,786 & 6,633 & 1,21 & 5,50 \\
\hline Histidina* & 1,261 & 0,631 & 2,022 & 1,01 & 2,00 \\
\hline Arginina* & 4,866 & 0,973 & 6,799 & 1,36 & 5,00 \\
\hline Ácido aspártico & 7,749 & & 8,892 & & \\
\hline Treonina* & 3,424 & 0,856 & 4,096 & 1,02 & 4,00 \\
\hline Serina & 3,604 & & 4,448 & & \\
\hline Ácido glutâmico & 10,092 & & 11,878 & & \\
\hline Prolina & 3,965 & & 4,227 & & \\
\hline Glicina & 6,488 & & 8,349 & & \\
\hline Alanina & 5,587 & & 6,052 & & \\
\hline Cistina & 0,360 & & 0,891 & & \\
\hline Valina* & 3,424 & 0,685 & 2,945 & 0,59 & 5,00 \\
\hline Metionina* & 1,802 & 0,515 & 2,468 & 0,71 & 3,50 \\
\hline Isoleucina* & 3,064 & 0,766 & 2,605 & 0,65 & 4,00 \\
\hline Leucina* & 5,046 & 0,721 & 5,619 & 0,80 & 7,00 \\
\hline Tirosina & 1,982 & & 2,470 & & \\
\hline Fenilalanina* & 2,703 & 0,630 & 3,124 & 0,73 & 4,29 \\
\hline Proteína Bruta (\%) bs & 55,49 & & 52,69 & & \\
\hline
\end{tabular}

*Aminoácido essencial. EQ = (g de aminoácido/100g de proteína teste) /(g de aminoácido/100g de proteína padrão $\mathrm{FAO})$.

\section{Discussão}

Com a produção da silagem pode-se afirmar que, conforme já exposto por Vidotti et al. (2002) e Arruda et al. (2001), o processo para obtenção de silagem é simples, prático e econômico, não requerendo equipamentos e procedimentos custosos, como os empregados na produção de farinha de peixe pelo processo termomecânico industrial.

Em silagem química elaborada por Benites (2003) onde os tempos de ensilado foram de 15 e 30 dias, utilizando como agente acidificante o mesmo ácido na mesma concentração (10\% p/v), foram obtidos valores de $\mathrm{pH}$ entre 4,0 e 4,3, valores estes muito semelhantes aos encontrados neste trabalho. Estudo desenvolvido por Seibel \& Souza-Soares (2003), com o tempo de ensilado de pescado de 15 dias, 
utilizando como agente acidificante o mesmo ácido, contudo, em maior concentração (15\% p/v), apresentou valores de $\mathrm{pH}$ entre 3,16 e 3,54. Dados de Costa et al. (2001), empregando o mesmo ácido a uma concentração de $17 \%$ (p/v), na silagem de pescado, mostram que o $\mathrm{pH}$ não foi superior a 3,5 durante todo o experimento, indicando que esta quantidade foi suficiente para a redução e manutenção de pH ácido.

Conforme Beraquet \& Galacho (1983), o grau de hidrólise deveria aumentar com o tempo de estocagem de silagem, pois durante o processo de obtenção da mesma, as proteínas são degradadas para peptídeos de baixo peso molecular e aminoácidos livres pela ação de enzimas naturalmente presentes no pescado; consequentemente a fração solúvel aumenta, ou seja, fração que não é precipitada pelo ácido tricloroacético, o que pode ser observado neste trabalho e em outros que diferem no grau, mas mantém a tendência. Este é o caso do trabalho de Costa et al. (2001) que empregando o mesmo resíduo de pescado, porém com média de temperatura de $17^{\circ} \mathrm{C}$ ao longo dos 28 dias de processo, obtiveram o teor de nitrogênio solúvel de 38,54\% em relação ao nitrogênio total. O teor de nitrogênio solúvel obtido neste estudo foi menor do que o encontrado por Tatterson \& Windsor (1974), que utilizaram "sprats" (Sprattus sprattus) inteiro. Os autores relataram que após 10 dias de estocagem (ensaio conduzidos a $23^{\circ} \mathrm{C}$ ), o nitrogênio solúvel constituía cerca de $75 \%$ do nitrogênio total. Acredita-se que a diferença decorra do fato de algumas espécies de pescados possuírem mais enzimas que outras. Beraquet \& Galacho (1983) encontraram para silagens de resíduos de pescada e de mistura de pescados uma porcentagem de nitrogênio solúvel em relação ao total de 38\%, e para silagens de resíduos de sardinha 32\%, utilizando temperatura em torno $20^{\circ} \mathrm{C}$, após 14 dias, valores inferiores aos encontrados nesse experimento. Segundo Maia et al. (1998) a liquefação leva mais de 20 dias para ocorrer e de acordo com Espe \& Lied (1999) o resíduo composto de vísceras, fração esta rica em enzimas, solubiliza-se mais rápido do que aquele composto de frações enzimaticamente mais pobres.

A coloração final da silagem, marrom-claro, também foi verificado na silagem química obtida por Benites (2003) e Oliveira et al. (2006). A composição química do pescado varia entre as espécies e também de peixe para peixe de uma mesma espécie; diversas causas podem ser responsáveis, como tamanho, sexo, área geográfica, ciclo metabólico, mobilidade, época do ano, parte do pescado do qual se obteve a amostra e a alimentação. $O$ teor de proteína bruta em peixes de água doce varia de 12 a $28 \%$, tendo como principal constituinte a água (66\% a $84 \%$ ), os lipídios de $0,1 \%$ a $22 \%$ e as substâncias minerais, de $0,8 \%$ a 2,9\%. Diferentes espécies de pescado e o tipo de músculo, branco ou escuro, podem ser os fatores responsáveis pelos valores de proteínas desses peixes (Sales, 1995). Segundo Maia et al. (1998), o extrato etéreo presente na silagem pode ser utilizado em substituição ao óleo de soja nas rações, sendo fonte de ácidos graxos poliínsaturados, ressaltando as reações de oxidação ou até mesmo inibidas com a utilização de antioxidante no início do processo e armazenamento do produto, fazendo com que o teor de lipídios não seja prejudicial.

Segundo a Petenuci et al. (2008) a composição química de diferentes tipos de silagem química, produzidas com pescado inteiro variam entre 52,6 e $66,5 \%$ de proteína; 4,2 e 16,6\% de extrato etéreo, 11,7 e $30,0 \%$ de minerais. O teor de minerais da farinha de silagem $23,12 \%$ é menor do que os da farinha de pescado comercial 35,4\%, devido à utilização de resíduos da pesca apresentar teores maiores de minerais que os rejeitos da pesca, sendo, portanto, a silagem produzida uma boa fonte desses nutrientes. A composição proximal da farinha de silagem química de resíduos de castanha (Umbrina canosai) com adição de ácido acético (10\% p/v), obtida por Benites (2003) apresentou 66,16\% de proteína bruta; 9,15 $\%$ de extrato etéreo, $21,12 \%$ de minerais. Seibel \& Souza-Soares (2003), em silagem elaborada em condições semelhantes; porém, com decantação natural e retirada da porção líquido-oleosa, a composição proximal de farinha de silagem química de resíduos de pescada foguete (Cynoscion guatacupa) com adição de ácido acético (15\% p/v), variou entre 46,25 e 56,7\% de proteína bruta; 13,6 e $14,5 \%$ de extrato etéreo e 16,0 e $18,2 \%$ de minerais. A composição proximal de farinha de silagem química de resíduos de corvina, produzida por Costa et al. (2001), com adição de ácido acético (17\% p/v), variou entre 59,9 e 61\% de proteína bruta; 9,9 e 10,6\% de extrato etéreo e 29,4 e $29,8 \%$ de minerais. Estes dados evidenciam claramente as diferenças entre as composições químicas que variam de acordo com o tipo de matéria-prima, se resíduo ou descarte, os procedimentos realizados e a época do ano, indicando que o processo de silagem pode ser mais seletivo e adequado aos aspectos nutricionais desejados. 
O teor de cálcio e fósforo no processo de silagem é devido principalmente à porção óssea do pescado, sendo que estes elementos estão na forma de fosfato-tricálcico e carbonato de cálcio, em teores relativamente altos (Geron et al., 2007).

Stone \& Hardy (1986) avaliaram o teor de cálcio de algumas espécies de peixes e concluíram que é extremamente variável entre as espécies, e entre a carne e vísceras do peixe também demonstrada a variação pelos mesmos autores. O peixe inteiro tem um teor muito mais alto de cálcio do que a carne ou vísceras, porque a riqueza de cálcio é associada com o esqueleto e as escamas, os quais contêm fosfato tricálcico e carbonato de cálcio. Kompiang et al. (1980) confirmaram a importância das escamas como fonte de cálcio descobrindo que a sardinha continha $4,6 \%$ de cálcio no peixe inteiro, e somente $2,5 \%$ de cálcio quando as escamas eram removidas. Essas flutuações estão associadas com numerosos fatores incluindo idade e sexo do peixe, como também o teor de cálcio na água.

Sales (1995) apresenta valores de minerais bem menores do que os descritos neste trabalho $(1,42 \%$ $\mathrm{Ca}, 0,97 \% \mathrm{P}, 0,61 \% \mathrm{Mg}$ e $0,07 \% \mathrm{Fe}$ ), devido ao fato de que o autor produziu uma silagem biológica de despesca de tilápia. O ácido glutâmico, ácido aspártico e a glicina são os aminoácidos encontrados em maior concentração para a silagem elaborada, assim como os encontrados por Arruda et al. (2001), Vidotti et al. (2002) e Vidotti et al. (2003); porém, estes autores trabalham com silagem química dos descartes da comercialização de peixes de água doce, apresentando teores menores de triptofano, ácido aspártico e glutâmico e semelhantes de alanina, valina e tirosina.

A farinha de silagem de pescado apresentou teores maiores de todos os aminoácidos do que relatado por Benites (2003), que produziu silagem química nas mesmas condições que neste trabalho, porém, utilizou resíduos de pescado marinho. Geron et al. (2007) mencionam que silagens possuem menor teor de fenilalanina e tirosina, pois estes são solúveis em solução aquosa. Quando se comparam os níveis de aminoácido da farinha de silagem de pescado com a farinha tradicional, percebe-se que em geral, este último apresenta valores mais elevados com exceção dos aminoácidos essenciais triptofano, valina e isoleucina. Sendo que o triptofano apresentou maiores teores na farinha de silagem de pescado, quando comparado com o padrão da FAO (1985). O escore químico da silagem de pescado é semelhante ao encontrado por Benites (2003), onde o aminoácido limitante na farinha de silagem de pescado foi a metionina $(0,515)$ e para a farinha de pescado comercial a valina $(0,59)$. Conforme preconizado por Tacon (1994), os teores de lisina, cistina e metionina devem ser observados, prioritariamente, na elaboração de rações para peixes, o mesmo autor considera como aminoácido limitante apenas os que estiverem $30 \%$ abaixo das exigências mínimas. Tomando-se este fato como base a farinha de a silagem de pescado (voga) elaborada não apresenta deficiência em nenhum aminoácido essencial.

\section{Conclusões}

O aproveitamento dos rejeitos da pesca de água doce (Cyphocharax voga) na forma de silagem química pode contribuir para diminui da poluição ambiental, tornando-se uma alternativa ecológica e viável para o piscicultor, que pode utilizar a silagem como ingrediente protéico, com boa fonte de minerais e aminoácidos para elaboração de dietas balanceadas para o cultivo de peixes.

\section{Referências bibliográficas}

AOAC. (2005). - Association Official Analytical Chemist (2005) (Official Methods of Analysis (18th ed.) ed.). Gaitherburg, Maryland, USA: AOAC.

Arruda, L. F., Borghesi, R. \& Oetterer, M. (2001). O preparo da silagem de pescado. Panorama da Aqüicultura, 11(65):34-36.

Arruda, L. F. \& Oetterer, M. (2005). Silagem ácida-Uma tecnologia alternativa para aproveitamento do resíduo do processamento do pescado. Revista de Aquicultura \& Pesca, 14(1):30-33.

Beerli, E. L., Beerli, K. M. C. \& Logato, P. V. R. (2004). Silagem ácida de resíduos de truta (Oncorhynchus mykiss), com utilização de ácido muriático. Ciência e Agrotecnologia, 28(1):195198.

Benites, C. I. (2003). Farinha de silagem de resíduos de pescado: Elaboração, complementação com farelo de arroz e avaliação biológica em diferentes espécies. Master of Science, Universidade Federal do Rio Grande do Sul, Porto Alegre, Rio Grande do Sul, Brasil. 
Beraquet, N. J. \& Galacho, S. A. A. (1983). Composição, estabilidade e alterações na fração protéica e no óleo de ensilados de resíduos de peixe e de camarão. Coleção ITAL, 13149-74.

Conte Júnior, C. A. \& Rodrigues, B. L. (2013). Tecnologia avançada na conservação de pescado. Revista Animal Business Brasil, 3(7):50-56.

Costa, C. S., Schoffen, D. B. \& Silva, L. A. F. (2001). Estudo do processamento de silagem e da possibilidade de sua implantação industrial. $(1,1)$. Rio Grande, Rio Grande do Sul, Brasil.

Cunha, D. C. \& Pinto, L. A. (2012). Estudo da etapa de fracionamento via "Winterização" seca no processo de refino do óleo de pescado. VETOR - Revista de Ciências Exatas e Engenharias, 12, 2.

Das, H. K., Hattula, M. T., Myllymäki, O. M. \& Mälkki, Y. (1993). Effects of formulation and processing variables on dry fish feed pellets containing fish waste. Journal of the Science of Food and Agriculture, 61(2):181-187.

Espe, M. \& Lied, E. (1999). Fish silage prepared from different cooked and uncooked raw materials: chemical changes during storage at different temperatures. Journal of the Science of Food and Agriculture, 79(2):327-332.

FAO. (1985). Report of joint FAO/WHO/ONU Expert Consulation Technical Report, 1985, Geneve. Energy and protein requeriments. Geneve: FAO/WHO and the United Nations University, (FAO Series n. 724).

Garcia, A. M. \& Vieira Sobrinho, J. P. (2001). O aumento da diversidade de peixes no estuário da Lagoa dos Patos durante o episódio El Niño 1997-1998. Atlântica, 23123-152.

Geron, L. J. V., Zeoula, L. M., Vidotti, R. M., Matsushita, M., Kazama, R., Neto, S. F. C. \& Fereli, F. (2007). Chemical characterization, dry matter and crude protein ruminal degradability and in vitro intestinal digestion of acid and fermented silage from tilapia filleting residue. Animal Feed Science and Technology, 136(3-4):226-239. doi: 10.1016/j.anifeedsci.2006.09.006

Gupta, M. V. \& Acosta, B. O. (2004). A review of global tilapia farming practices. Aquaculture Asia, 9(1):7-12.

Hartz, S. M., Martins, A. G. \& Peret, A. C. (1994). Fecundidade de Cyphocharax voga (Hensel, 1869) na lagoa Emboaba, Rio Grande do Sul, Brasil (Characiformes, Curimatidae). Iheringia, Série Zoologia, 76(1):161-165.

Kompiang, I. P., Yushadi, S. \& Cresswell, D. C. (1980). Microbial fish silage: chemical composition, fermentation characteristics and nutritional value. In J. G. Disney \& D. James (Eds.), Fish silage production and its use (pp. 38-43). Rome, Italy: FAO.

Maia, W. M., Nunes, M. L., Figueiredo, M. J. \& Bragagnolo, N. (1998). Caracterização da fração lipídica de silagem de resíduos de tilápia para utilização em rações para a aqüicultura. Simpósio Brasileiro de Aquicultura, 1055-64.

Miranda, M. R. J. \& Maggi, R. C. (1991). Utilización de desechos sólidos de la industria pesquera. Alimentación Equipos y Tecnologia, 689-94.

Oetterer, M., D'Arce, M. A. B. R. \& Spoto, M. (2006). Fundamentos de ciência e tecnologia de alimentos. Barueri - São Paulo: Editora Manole Ltda.

Oliveira, M. M., Pimenta, M. E. S. G., CAMARGO, A. C. S., Fiorini, J. E. \& Pimenta, C. J. (2006). Silagem de resíduos da filetagem de tilápia do nilo (Oreochromis niloticus), com ácido fórmicoanálise bromatológica, físico-química e microbiológica. Ciência e Agrotecnologia, 30(6):1218-1223.

Petenuci, M. E., Stevanato, F. B., Visentainer, J. E. L., Matsushita, M., Garcia, E. E., De Souza, N. E. \& Visentainer, J. V. (2008). Fatty acid concentration, proximate composition, and mineral composition in fishbone flour of Nile Tilapia. Archivos Latinoamericanos de Nutricion, 58(1):8790.

Pezzato, L. E., Milanese, C., Barros, M. M., Carrote, C. R. \& ezzato, A. C. (1995). Estabilidade química de dietas para organismos aquáticos confeccionadas com aglutinantes nutritivos. Boletim do Instituto de Pesca, 22(1):125-131.

Sales, R. O. (1995). Processamento, caracterização química e avaliação nutricional da silagem da despesca da tilápia do Nilo (Oreochromis niloticus) em dietas experimentais com ratos. $\mathrm{PhD}$, Universidade Estadual de Campinas, Campinas., São Paulo, Brasil. 
Seibel, N. F. \& Souza-Soares, L. A. (2003). Produção de silagem química com resíduos de pescado marinho. Brazilian Journal of Food Technology, 6(2):333-337.

Sgarbieri, V. C. (1987). Alimentação e nutrição: fator de saúde e desenvolvimento. Campinas, São Paulo, Brasil: UNICAMP.

Spackman, D. H., Stein, W. H. \& Moore, S. (1958). Automatic recording apparatus for use in chromatography of amino acids. Analytical Chemistry, 30(7):1190-1206.

Stone, F. E. \& Hardy, R. W. (1986). Nutritional value of acid stabilised silage and liquefied fish protein. Journal of the Science of Food and Agriculture, 37(8):797-803.

Tacon, A. G. J. (1994). Feed ingredients for carnivorous fish species: Alternatives to fishmeal and other fishery resources. Rome, Italy: FAO.

Tatterson, I. N. \& Windsor, M. L. (1974). Fish silage. Journal of the Science of Food and Agriculture, 25(4):369-379.

Tedesco, M. J., Gianello, C., Bissani, C. A., Bohnen, H. \& Volkweiss, S. J. (1995). Análises de solo, plantas e outros materiais (Vol. 174). Porto Alegre, Rio Grande do Sul, Brasil: Universidade Federal de Porto Alegre.

Vari, R. P. (1988). The Curimatidae, a lowland neotropical fish family (Pisces: Characiformes): distribution, endemism, and phylogenetic biogeography. Paper presented at the Neotropical Distribution Patterns: Proceedings of a Workshop, Rio de Janeiro, Brasil.

Vidotti, R. M., Carneiro, D. J. \& Viegas, E. (2002). Growth rate of pacu, Piaractus mesopotamicus, fingerlings fed diets containing co-dried fish silage as replacement of fish meal. Journal of Applied Aquaculture, 12(4):77-88.

Vidotti, R. M., Viegas, E. M. M. \& Carneiro, D. J. (2003). Amino acid composition of processed fish silage using different raw materials. Animal Feed Science and Technology, 105(1-4):199-204.

Recebido: 6 de junho, 2019.

Aprovado: 5 de julho, 2019.

Publicado: 30 de agosto, 2019.

Licenciamento: Este artigo é publicado na modalidade Acesso Aberto sob a licença Creative Commons Atribuição 4.0 (CC-BY 4.0), a qual permite uso irrestrito, distribuição, reprodução em qualquer meio, desde que o autor e a fonte sejam devidamente creditados. 